\title{
Increasing smear positive-pulmonary tuberculosis cases by strengthening district TB coordinating team in low case-detection provinces, Thailand
}

\begin{abstract}
Background: Tuberculosis (TB) is a communicable infectious diseases and remains a major global health problem as the cause of death from an infectious disease worldwide. This study was increased TB cases notification by strengthening the system of district TB coordinating team.

Materials and methods: The research was mixed method, Quasi - Experimental study with two -group control and intervention pre-post analysis. The two low TB-case notification provinces in public health region 7 were purposive selected and two districts from each province was random selected to be the area of the study. Selapoom district, Roiet province and Banpai district, Khonkaen province were the study sites for intervention and contro group respectively. The sample size included all of TB suspected cases in both group. Data collected from the suspected TB cases form case record form in each district hospital in 9 month period of base line before and after intervention period in both group. The satisfaction questionnaire collected from participants in district TB coordinating team. The curriculum for TB knowledge applied from the standard of National TB program (NTP ) for teaching in the intervention workshop. Focus group discussion was done about system implementation. Data analysis by descriptive statistic, chi square test, focus group analysis was used in qualitative study.
\end{abstract}

Results: The district TB coordinating team was set up in the intervention hospital included of 14 health personnel from hospital, district health office and health center. The work flow and monitoring system was implemented by the district team in intervention group in 9 months period. There were 838 and 324 suspected TB cases in baseline 9 months before the study and 769 and 379 of suspected TB cases in post 9 months after intervention period among control and intervention hospital respectively. The most age group of TB suspected cases were more than 60 year and the most occupation were agriculturists in both group In both group found that the factors of gender, chest radiography, sputum microscopy, chest radiography with sputum microscopy, chest radiography with completed microscopic examinations, were associated statistically significant at the 0.05 level. For the relative risk of TB notification cases in control hospital ( $\mathrm{RR}=0.74,95 \% \mathrm{CI} 0.54-1.03, p$-value 0.07 ) and intervention hospital ( $\mathrm{RR}=1.61,95 \% \mathrm{CI} 1.04-2.51, p$-value 0.03$)$ defined that in the hospital with non-intervention provided had a $25 \%$ reduction of TB notification cases and in the hospital with intervention provided had a $61 \%$ increase of TB notification cases.. Focus group analysis concluded that district TB coordinating team was benefit in district level and helping team to monitoring of TB control program. The coordinating system especially having TB coordinator was the most satisfaction from the participants.

Conclusion: Strengthening district TB coordinating team and the coordinating network in hospital, district health office and health center help to increase TB case notification and percent of suspected tuberculosis cases to complete the investigation in district level.
Volume 5 Issue 6 - 2018

\author{
Sasithorn Tangsawad, Surasak \\ Taneepanichskul \\ College of Public Health Sciences, Chulalongkorn University, \\ Thailand
}

Correspondence: Tangsawad S, College of Public Health Sciences, Chulalongkorn University, Institute building 2-3, Soi Chulalongkorn 62, Phyathai Rd, Pathumwan, Bangkok 10330 , Thailand, Tel +66 2218 8193, Fax +66 2255 6046, Email sasitth@gmail.com

Received: December 05, 2018 | Published: December 20, 2018

Keywords: smear positive pulmonary tuberculosis, district TB coordinating team

Abbreviations: COA, committee of Chulalongkorn University; $\mathrm{CI}$, confidential interval; CXR, chest x-ray; DOTS, directly observed treatment short course; IOC, item objective congruence; IPD, in patient department; MDR-TB, multidrug resistant tuberculosis; NTP, national tuberculosis control program; OPD, outpatient department; PTB, pulmonary tuberculosis smear positive case; RR, relative risk; SD, standard deviation; TB, tuberculosis; WHO, world health organization; XDR-TB, extensively-drug esistant tuberculosis; $\bar{X}$ : mean.

\section{Introduction}

Tuberculosis (TB) is a communicable infectious diseases and remains a major global health problem as the cause of death from an infectious disease worldwide. Nearly 20 years after the World Health Organization (WHO) declaration of TB as a global public health emergency, major progress has been made towards 2015 within the context of the Millionium Development Goals. ${ }^{1}$ Among the high burden countries, the gap between case notifications and the real incidents cases was caused from underreporting of diagnosed TB and under diagnosis due to failure to detect cases in health care facilities. ${ }^{2}$ Thailand is one of the 22 ranged tuberculosis (TB) high burden countries in the world and had about 86,000 TB incident cases and 110,000 TB prevalent cases and treatment success rate in TB was $85 \%$ in 2010 . Among these, 44,000 cases were smear positive which able to contagious and important in role of TB control program. These situation are further growing threat of drug resistant TB or multidrug 
resistant TB (MDR-TB). ${ }^{3}$ Thailand got full DOTS coverage and TB services are available in many hospitals. Thailand has the policy for expanding and enhancing TB diagnosis and care in all level in district settings. The community and sub-district level play role in DOT and home visit. The case notification rate of new smear positive TB in Thailand since 2010 to 2014 was under the estimate rate of WHO. The $5^{\text {th }}$ JIMM took place in August 2013, bringing together external experts and national staff to review the performance of TB care and prevention activities in different settings. The review team prioritized their main concerns in low case notifications in report system of TB cases in the national underreporting is significant and below estimated rates. ${ }^{4} \mathrm{We}$ expected that if suspected TB cases increase and completed investigation, confirmed TB cases will increase and include in the health service system leading to increasing of case notification rate. ${ }^{5}$

The objective of this study was increased TB cases notification by strengthening the system of district TB coordinating team.

\section{Definition}

Tuberculosis (TB): In this research defined only in pulmonary tuberculosis smear positive case (PTB $)^{5}$ diagnosed in the district hospital.

TB case notification: TB confirmed case and had been registered in the health surveillance system in the hospital. ${ }^{6}$

\section{Materials and methods}

The research was mixed method Quasi - Experimental study with two - group control and intervention pre - post analysis. The experimental group was strengthened and set up the system for TB coordinating system .The control group worked as routine for TB services. The focus group study in the participants with system implementation. The intervention was conducted in the 9 months period

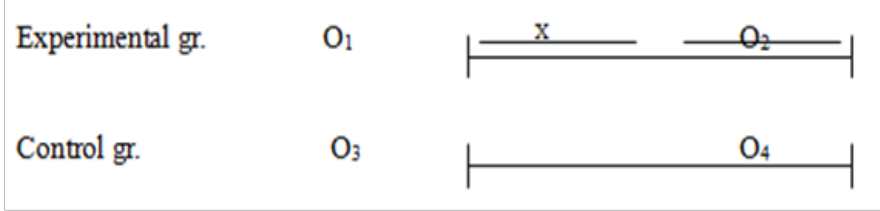

$\mathrm{O}_{1}, \mathrm{O}_{3}$ : Data collection before the study in intervention and control group, data will be collected in 9 months of base line.

$\mathrm{O}_{2}, \mathrm{O}_{4}$ : Data collection after the study in intervention and control group, data will be collected in 9 months period of the study.

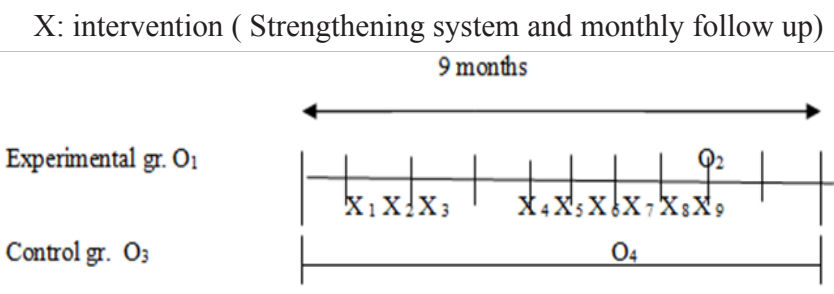

$\mathrm{O}_{1}, \mathrm{O}_{3}$ defined as the data collection before intervention in both experimental and control group by using case record form. The data included: age, sex, occupation, come by self or by refer from health center, get diagnosis by sputum examination and chest X-ray or not, get tracing or not and the diagnosis and registration.
$\mathrm{O}_{2}, \mathrm{O}_{4}$ defined as the data collection after intervention in both experimental and control group by using case record form. The data detail as the same as $\mathrm{O}_{1}, \mathrm{O}_{3}$

$\mathrm{X}_{1}$ defined as the empower work shop with 2 days schedule including the activities of TB knowledge and TB control in the first day and set up the system for suspected TB referral and tracing system in second day.

\section{$\mathrm{X}_{2}-\mathrm{X}_{9}$ defined as the monthly monitoring activities of the team}

\section{Sample and sample size}

The 2 low TB case notification provinces were purposive selected in the public health region 7 which case notification rate below WHO Estimation, Khon Kaen and Roi Et provinces were purposively selected to be the area for the study. The study was conducted between October 2016-June 2017. Selapoom hospital, Roi Et province was random selected for the study site for intervention group and Banpai hospital, Khon Kaen province was random selected for control group. The sampling flow chart as follow.

Sampling Flow Chart

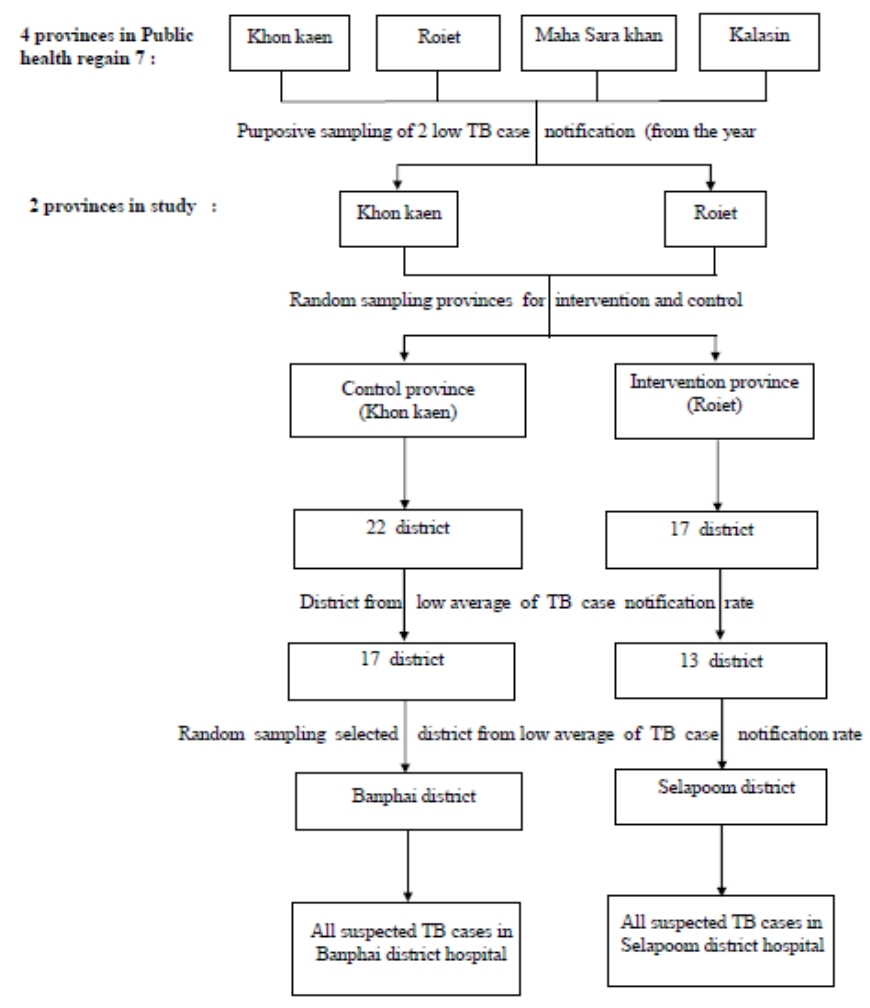

\section{Inclusion criteria and exclusion criteria}

Inclusion criteria for set up TB strengthening system were the participants from TB clinic in the hospital including of doctors and nurses, technician from Laboratory room, TB responsible personnel from district health office and health centers. Inclusion criteria for suspected TB cases were the record of suspected TB cases in adults 15 years and more in the hospital and record of suspected TB cases from TB01 TB05 TB09 records and referral document from health center. Exclusion criteria were the suspected TB cases which refered out to other hospital for further investigation. 


\section{Research instruments}

The case record form and the satisfaction questionnaire for participants about the implemented system. The satisfaction questionnaire of the system (14 item) was tested for content validity of Index of Item Objective Congruence (IOC) was more than 0.5 of each item from the expert of TB control programme. (The National TB programme manager ( 3 persons), The Regional TB programme manager (2 persons)). The Reliability was tested by Cronbach Alpha Coefficient is 0.92 in 30 pilot trial from TB health personnel in the area resemble the area of the study. The satisfaction level from all participants of the strengthening system scores were divided as follows: The score of 4.51-5.00 was highest level. The average score of 3.51-4.50 was high level. The score of 2.51-3.50 was moderate level and the score of 1.51-2.50 was low level. The score of 1:00 to 1:50 is lowest levels. The curriculum for TB knowledge applied from the standard of NTP for teaching program for the participants in the scheudule of intervention. The Focus group discussion guideline. The guidelines included the objective of the study, designing focus group question about the system implementation and how to improve the system.

\section{Data analysis}

Demographic data of TB suspected cases were analysed by descriptive statistics and chi-square test in pre and post of the intervention. The outcomes were compared after 9 months period of the study by risk ratio with $95 \%$ confidence interval. Focus group discussion was explored by item

\section{Ethical Consideration}

This study was followed by the detail of the approval of Ethical committee of Chulalongkorn University COA NO. 158/2016.

\section{Results}

There were 14 participants including in the setup of district TB co-ordinating team. 10 were female and 4 were male, 10 are from hospital 1 from district health office and 3 from health center. There are 2 doctors, 2 outpatient nurse, 2 TB clinic nurses, 1 technician from Laboratory room and 1 from district health office and 3 from health centers. Most age group was between 31-40 year. Most of education level was Bachelor degree. Most of them had the work time 1-5 year and 7 and 5 persons were trained for TB course in the past year and 1-5 year, 2 persons were trained for TB course in more than 6 year (Table 1).

Table I General characteristics of health personnel of district TB coordinating team

\begin{tabular}{lll}
\hline General information & $\mathrm{n}=14$ & Percentage \\
\hline Work place & & \\
Hospital & 10 & 74.43 \\
District health office & 1 & 7.14 \\
Health center & 3 & 21.43 \\
Sex & & \\
Male & 4 & 28.57 \\
Female & 10 & 71.43 \\
\hline
\end{tabular}

\begin{tabular}{|c|c|c|}
\hline General information & $n=14$ & Percentage \\
\hline \multicolumn{3}{|l|}{ Age (year) } \\
\hline $20-30$ & 1 & 7.14 \\
\hline $31-40$ & 6 & 42.86 \\
\hline $4 \mid-50$ & 5 & 35.71 \\
\hline$>51$ & 2 & 14.29 \\
\hline \multicolumn{3}{|l|}{ Education level } \\
\hline Bachelor degree & 9 & 64.29 \\
\hline Master degree & 5 & 35.71 \\
\hline \multicolumn{3}{|l|}{ Job position } \\
\hline Outpatient nurse & 2 & 14.29 \\
\hline TB clinic nurse & 2 & 14.29 \\
\hline Medical technologist & 1 & 7.14 \\
\hline District TB coordinator & 1 & 7.14 \\
\hline Health promoting hospital & 3 & 21.43 \\
\hline Medical doctor & 2 & 14.29 \\
\hline Health officer & 3 & 21.43 \\
\hline \multicolumn{3}{|l|}{ Work time (year) } \\
\hline$<1$ & 4 & 28.57 \\
\hline 5-Jan & 5 & 35.71 \\
\hline 10-Jun & 2 & 14.29 \\
\hline$>10$ & 3 & 21.43 \\
\hline \multicolumn{3}{|l|}{ Last training time (year) } \\
\hline$<1$ & 7 & 50 \\
\hline$I-5$ & 5 & 35.71 \\
\hline $6-10$ & 1 & 7.14 \\
\hline$>10$ & I & 7.14 \\
\hline
\end{tabular}

The intervention in the first day of the workshop schedule was TB knowledge training for all participants in intervention group including TB knowledge. The second day of workshop schedule was the TB system set up and the output of the workshop was the formation of a district TB co-ordinating team and flow of TB health service system in district level together with role and function of each participant as follow.

1) Work structure: Set up district $T B$ coordinating team including physician, nurses, medical technologist, district health personnel, health center personnel. The district TB co-ordinating team TB is responsible for collaborating and monitoring the work process together. Hospital TB coordinator coordinated in hospital and coordinated with district TB coordinator (district health office personnel).

2) Work process: by specified the process when suspected $T B$ cases have to be referred from the health center to the hospital. The personnel at health centers screen suspected cases and then referred them to the hospital by indications with referral document. 
2.1 The hospital set up a hospital TB coordinator (TB clinic nurse). The hospital TB coordinator had the role to follow up suspected TB cases to get complete investigation including chest radiography and microscopic examination by collaborating and sharing information with the outpatient department (OPD), in patient department (IPD), and medical technologist. The hospital TB coordinator also coordinated with the district health office to follow up suspected cases by health center team.

2.2 The health personnel from district health office was set up as district TB coordinator and had to monitor the health center for the follow up process of the suspected TB cases to get complete investigation at the hospital.

2.3 Monitoring and evaluation system: The district TB coordinating team set up regularly meeting to share information and solve problems together.

\section{Base line 9 month period}

All of suspected TB cases from control hospital was 838 records and 324 records from intervention hospital. In control hospital the mean age was 57.73 year, most was more than 60 year (49.76\%). 505 cases $(60.26 \%)$ were agriculturist. $688(82.10 \%)$ of suspected TB cases received CXR, 627 (74.82\%) received sputum examination and $429(68.42 \%)$ received schedule for both CXR and completed microscopy (three times for sputum microscopy). In intervention hospital, the mean age was 57.73 year, most was more than 60 year (48.77\%). 210 cases (64.81\%) were agriculturist. 300 (92.59\%) of suspected TB cases received CXR, $255(78.70 \%)$ received sputum examination and $176(80.36 \%)$ received schedule for both CXR and completed microscopy. Among all of suspected TB cases from control hospital and intervention hospital. The factors, of gender, chest radiography, and chest radiography with sputum microscopy were associated statistically significant at the 0.05 level (Table 2 ).

\section{After intervention 9 month period}

In control hospital, 769 records of suspected PTB cases reported in the hospital after the 9 months period of intervention .The mean age was 59.35 year, most was more than 60 year (53.71\%). 430 cases (55.92\%) were agriculturist. $753(97.92 \%)$ of suspected TB cases received CXR, 749(97.39\%) received sputum examination and 568 (73.86\%) received schedule for both CXR and completed microscopy (three times for sputum microscopic examinations). TB smear positive were diagnosed in 56 cases $(7.28 \%)$ and were registered for treatment at hospital 55 cases $(98.21 \%), 1$ cases $(1.79 \%)$ were referred to other hospital for treatment. In intervention hospital, 379 records of suspected PTB cases reported in the hospital. The mean age was 58.31 year, most was more than 60 year (50.66\%). 261 cases $(68.87 \%)$ were agriculturist. $353(93.14 \%)$ of suspected TB cases received CXR, $349(92.08 \%)$ received sputum microscopic examinations and 283 $(89.27 \%)$ received schedule for both CXR and completed microscopic examinations (three times for sputum microscopic examinations). TB smear positive were diagnosed in 51 cases $(13.46 \%)$ and were registered for treatment at hospital 48 cases $(94.11 \%)$, while 3 cases $(4.89 \%)$ were referred to other hospital for treatment. Among all of suspected TB cases from control hospital and intervention hospital, gender, chest radiography, and sputum microscopic examinations, the results revealed that chest radiography were associated statistically significant with sputum microscopic examinations at the 0.05 level (Table 3).

Table 2 Base line Characteristics of suspected TB cases in Control and Intervention hospital

\begin{tabular}{|c|c|c|c|c|c|c|}
\hline & \multicolumn{4}{|c|}{ Compare group } & \multirow{3}{*}{$\mathbf{X}^{2}$-test } & \multirow{3}{*}{ p-value } \\
\hline & \multicolumn{2}{|c|}{ Control hospital } & \multicolumn{2}{|c|}{ Intervention hospital } & & \\
\hline & $n=838$ & Percent & $n=324$ & Percent & & \\
\hline \multicolumn{7}{|l|}{ Gender } \\
\hline Male & 425 & 50.72 & 210 & 64.81 & 18.74 & $<0.001$ \\
\hline Female & 413 & 49.28 & 114 & 35.19 & & \\
\hline \multicolumn{7}{|l|}{ Age (year) } \\
\hline $15-20$ & 19 & 2.27 & 8 & 2.47 & & \\
\hline $21-30$ & 59 & 7.04 & 21 & 6.48 & & \\
\hline $31-40$ & 72 & 8.59 & 25 & 7.72 & & \\
\hline $4 \mid-50$ & 104 & $|2.4|$ & 54 & 16.67 & 4.01 & 0.547 \\
\hline $51-60$ & 167 & 19.93 & 58 & 17.9 & & \\
\hline \multirow[t]{4}{*}{$>60$} & 417 & 49.76 & 158 & 48.77 & & \\
\hline & \multicolumn{2}{|c|}{$\bar{X}=57.73$} & \multicolumn{2}{|c|}{$\bar{X}=57.75$} & & \\
\hline & \multicolumn{2}{|c|}{$(S . D .=17.09)$} & \multicolumn{2}{|c|}{$($ S.D. $=17.287)$} & & \\
\hline & $\operatorname{Min}=15$ & $\operatorname{Max}=92$ & $\operatorname{Min}=15$ & $\operatorname{Max}=90$ & & \\
\hline \multicolumn{7}{|l|}{ Occupation } \\
\hline Agriculturist & 505 & 60.26 & 210 & 64.81 & & \\
\hline Employer & 205 & 24.46 & 60 & 18.52 & 9.97 & 0.41 \\
\hline
\end{tabular}

Citation: Tangsawad S, Taneepanichskul S. Increasing smear positive-pulmonary tuberculosis cases by strengthening district TB coordinating team in low casedetection provinces, Thailand. J Lung Pulm Respir Res. 2018;5(6):202-210. DOI: 10.15406/jlprr.2018.05.00192 


\begin{tabular}{|c|c|c|c|c|c|c|}
\hline & \multicolumn{4}{|c|}{ Compare group } & \multirow{3}{*}{$\mathbf{X}^{2}$-test } & \multirow{3}{*}{ p-value } \\
\hline & \multicolumn{2}{|c|}{ Control hospital } & \multicolumn{2}{|c|}{ Intervention hospital } & & \\
\hline & $n=838$ & Percent & $n=324$ & Percent & & \\
\hline Government officer & 10 & 1.19 & 5 & 1.54 & & \\
\hline Commercial & 20 & 2.39 & 2 & 0.62 & & \\
\hline Other & 98 & 11.7 & 47 & $|4.5|$ & & \\
\hline \multicolumn{7}{|l|}{ Chest radiography } \\
\hline Yes & 688 & 82.1 & 300 & 92.59 & 20.2 & $<0.001$ \\
\hline No & 150 & 17.9 & 24 & 7.41 & & \\
\hline \multicolumn{7}{|l|}{ sputum microscopy } \\
\hline Yes & 627 & 74.82 & 255 & 78.7 & & \\
\hline $\begin{array}{l}\text {-completed by } \\
\text { schedule }\end{array}$ & 429 & 51.19 & 176 & 69.01 & 1.92 & 0.16 \\
\hline $\begin{array}{l}\text { - Not completed by } \\
\text { schedule }\end{array}$ & 198 & 48.81 & 79 & 30.99 & & \\
\hline No & 211 & 25.18 & 69 & 21.3 & & \\
\hline \multicolumn{7}{|c|}{ Chest radiography with sputum microscopy } \\
\hline Yes & 597 & 84.16 & 225 & 75 & 8.87 & 0.03 \\
\hline No & 91 & 15.84 & 75 & 25 & & \\
\hline \multicolumn{7}{|c|}{ Chest radiography with completed microscopy by schedule } \\
\hline Yes & 429 & 68.42 & 176 & 80.36 & 0.042 & 0.83 \\
\hline No & 198 & 31.58 & 79 & 19.64 & & \\
\hline
\end{tabular}

Table 3 Characteristics of suspected TB cases in control and intervention hospital after intervention period

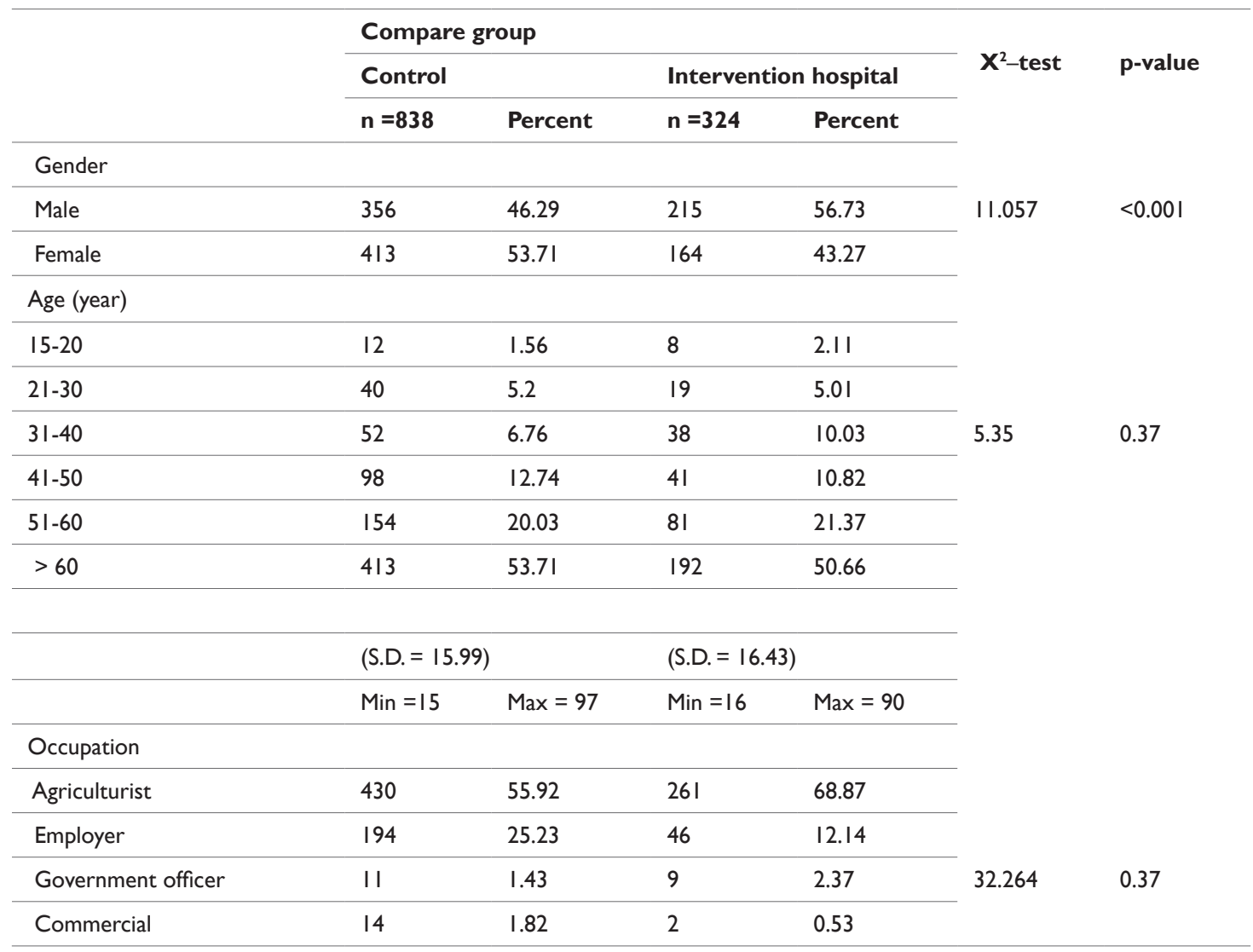

Citation: Tangsawad S, Taneepanichskul S. Increasing smear positive-pulmonary tuberculosis cases by strengthening district TB coordinating team in low casedetection provinces, Thailand. J Lung Pulm Respir Res. 2018;5(6):202-210. DOI: I0.15406/jlprr.2018.05.00192 
Table Continued

\begin{tabular}{|c|c|c|c|c|c|c|}
\hline & \multicolumn{4}{|c|}{ Compare group } & \multirow{3}{*}{$X^{2}$-test } & \multirow{3}{*}{ p-value } \\
\hline & \multicolumn{2}{|l|}{ Control } & \multicolumn{2}{|c|}{ Intervention hospital } & & \\
\hline & $n=838$ & Percent & $n=324$ & Percent & & \\
\hline Other & 120 & 15.6 & 61 & 16.09 & & \\
\hline \multicolumn{7}{|l|}{ Chest radiography } \\
\hline Yes & 753 & 97.92 & 353 & 93.14 & \multirow[t]{4}{*}{16.45} & \multirow[t]{4}{*}{$<0.001$} \\
\hline No & 16 & 2.08 & 26 & 6.86 & & \\
\hline \multicolumn{5}{|l|}{ sputum microscopy } & & \\
\hline Yes & 749 & 97.39 & 349 & 92.08 & & \\
\hline -completed by schedule & 568 & 75.83 & 283 & 81.08 & \multirow[t]{4}{*}{17.215} & \multirow[t]{4}{*}{$<0.001$} \\
\hline - not completed by schedule & 181 & 24.17 & 66 & 18.92 & & \\
\hline No & 20 & 2.61 & 30 & 7.92 & & \\
\hline \multicolumn{5}{|l|}{$\begin{array}{l}\text { Chest radiography with sputum } \\
\text { microscopy }\end{array}$} & & \\
\hline Yes & 588 & 76.46 & 299 & 84.7 & \multirow[t]{3}{*}{9.92} & \multirow[t]{3}{*}{0.002} \\
\hline No & 181 & 23.54 & 54 & 15.3 & & \\
\hline \multicolumn{5}{|c|}{ Chest radiography with completed microscopy by schedule } & & \\
\hline Yes & 568 & 73.86 & 283 & 89.27 & \multirow[t]{2}{*}{6.897} & \multirow[t]{2}{*}{0.009} \\
\hline No & 201 & 26.14 & 66 & 10.73 & & \\
\hline
\end{tabular}

There were 82 TB notification cases in base line data and 56 cases after nine months period from control hospital and there were $27 \mathrm{~TB}$ notification cases in base line data and 51cases after nine months period from intervention hospital. The relative risk of TB notification cases was 0.74 compare with base line (95\% CI 0.54-1.03, p-value 0.07). In intervention hospital, the relative risk of PTB confirmed cases was 1.61 compare with base line (95\% CI 1.04-2.51, p-value $0.03)$. In hospital with non-intervention provided after nine months period had a $25 \%$ reduction of TB notification cases. Hospital with intervention provided after nine months period had a $61 \%$ increase of TB notification cases (Table 4).

\section{The satisfaction level for intervention and system} development

The satisfaction for the issue of knowledge of the training were at the high level in the item of topics and contents $(\bar{X}=4.29$, S.D. $=0.66)$, knowledge and skills of the trainer $(\bar{X}=4.43$, S.D. $=0.64)$ , benefit of training $(\bar{X}=4.36$, S.D. $=0.63)$ and the duration $(\bar{X}=3.57$, S.D. $=0.75)$. The satisfaction for the issue of system development and strengthening of tuberculosis patient referral System were at high level in the item of referral system for suspected tuberculosis from health center to hospitals ( $\bar{X}=4.07$, S.D. $=0.47$ ), used to work properly $(\bar{X}$ $=3.93$, S.D. $=0.82)$, benefit for the health service $(\bar{X}=4.21$, S.D. $=$ $0.69)$, the coordination of district tuberculosis coordinator and health center $(\bar{X}=4.14$, S.D. $=0.86)$ and health center follow up system $(\bar{X}$ $=4.00$, S.D $=0.67)$. The satisfaction about the monitoring in meeting once a month was at high level. $(\bar{X}=3.64$, S.D. $=0.92)$. Over all of the implemented system had benefit to work and agreement with the strengthening the monitoring system from participants were also at high level $(\bar{X}=4.36$, S.D. $=0.63)$ (Table 5).

\section{Focus group discussion analysis}

The characteristics of focus group discussion were 11 participants from the district TB co ordinating team. 9 were female and 2 were male, 7 were from hospital 1 from district health office and 3 from health center. 1 participant was 20-30 year, 6 participants were 3140 year, 4 participants were $41-50$ year.9 participants were bachelor degree, and 2 were master degree. 4 participants had work time less than 1 year, 4 participants had work time 1-5 year and 3 had work time 6-10 year. 8 participants were trained for TB course in the past year and 1-5 year, 3 persons were trained for TB course in the past 1-5 year.

\section{Opinion about TB knowledge in training program.}

All participants mentioned that TB training was essential for TB control program in district level. The topics and contents of the lecture were consistent with the objectives of the system strengthening and appropriate for the development of knowledge and skills of the staff.

"The knowledge from the training is useful for TB prevention and control."

\section{(Respondent from hospital)}

"The knowledge is suitable and proper for related health personnel in district level." (Respondent from health center)

For the opinion for training improvement, the participants recommended that training program should be regularly and adding some issue related with TB control program. This suggestion could be caused from the reason that the health personnel who work in TB clinic or at the hospital and at the health center had the high turnover rate. From this study, the training time of participants varied from 1 to 10 years. 
Table 4 Relative risk of TB notification cases between control and intervention hospital compare

\begin{tabular}{|c|c|c|c|c|c|}
\hline Hospital & $\begin{array}{l}\text { TB } \\
\text { notification }\end{array}$ & $\begin{array}{l}\text { Percent } \\
(\%)\end{array}$ & $\begin{array}{l}\text { Relative Risk } \\
\text { (RR) }\end{array}$ & $95 \% \mathrm{Cl}$ & p-value \\
\hline \multicolumn{6}{|l|}{ Control } \\
\hline 9 month of study & 56 & 7.28 & 0.74 & $0.54-1.03$ & 0.07 \\
\hline Base line & 82 & 9.79 & 1 & & \\
\hline \multicolumn{6}{|l|}{ Intervention } \\
\hline 9 month of study & 51 & 13.46 & 1.61 & $|.04-2.5|$ & 0.03 \\
\hline Base line & 27 & 8.33 & I & & \\
\hline
\end{tabular}

Table 5 Satisfaction level of the participants in district TB coordination team

\begin{tabular}{|c|c|c|c|c|c|c|c|c|}
\hline \multirow{2}{*}{ Item } & & \multicolumn{5}{|c|}{ Satisfaction level } & \multirow{2}{*}{$\begin{array}{l}\text { Mean } \\
(\bar{X})\end{array}$} & \multirow{2}{*}{ S.D. } \\
\hline & & Highest (5) & High (4) & Medium (3) & Low (2) & Lowest (I) & & \\
\hline I. & \multicolumn{8}{|c|}{ Knowledge of the training } \\
\hline I.I. & Topics and contents & $5(35.7 \mathrm{I})$ & $8(57.14)$ & I (7.|4) & & & 4.29 & 0.66 \\
\hline $\mathrm{I} .2$ & Skills of the trainer. & $7(50.00)$ & $6(42.86)$ & I (7.|4) & & & 4.43 & 0.64 \\
\hline I.3. & Benefit & $7(42.86)$ & $6(50.00)$ & I (7.14) & & & 4.36 & 0.63 \\
\hline $\mathrm{I} .4$. & Duration & I (7.|4) & $7(50.00)$ & $5(35.7 \mathrm{I})$ & I (7.|4) & & 3.57 & 0.75 \\
\hline
\end{tabular}

2. System Development and Strengthening of Tuberculosis Patient referral System

2.I. Referral system

\begin{tabular}{|c|c|c|c|c|c|c|c|}
\hline \multirow{2}{*}{$\begin{array}{l}2.1 .1 . \\
2.1 .2 .\end{array}$} & Health center & 2 (14.29) & II (78.57) & I (7.I4) & 4.07 & 0.47 & high \\
\hline & Can be used & $4(28.57)$ & & $5(35.7 !)$ & 393 & 082 & high \\
\hline $2 \mid 3$ & & & & & & & \\
\hline & Benefit to the & 5 (35.7I) & $7(50.00)$ & $2(14.29)$ & 4.21 & 0.369 & high \\
\hline
\end{tabular}

2.2. Tuberculosis investigation and coordination system

2.2.1. Tuberculosis

Coordinator in $\quad 10(71.43) \quad 4(28.57)$

Hospital

4.7I $\quad 0.46 \quad$ highest

2.2.2. Hospital and

the district $\quad 9(64.29) \quad 5(35.7 I)$

$4.64 \quad 0.49 \quad$ highest

health office

2.2.3. District health

office and heal- $\quad 6(42.86) \quad 4(28.57) \quad 4(28.57)$

th center

2.2.4. Follow up $3(21.43) \quad 8(57.14) \quad 3(21.43)$

$\begin{array}{llll}\text { system } & 3(21.43) & 8(57.14) & 3(21.43)\end{array}$

.

2.3. Monitoring

$\begin{array}{llllll}\text { 2.3.I. } & \text { The duration of } \\ \text { meeting } & 3(21.43) & 4(28.57) & 6(42.86) & \text { I (7.14) } & 3.64\end{array}$

2.4. Over all

\begin{tabular}{|c|c|c|c|c|c|c|c|}
\hline 2.4.1. & Benefit to work. & $6(42.86)$ & $7(50.00)$ & I (7.14) & 4.36 & 0.63 & high \\
\hline 2.4.2. & $\begin{array}{l}\text { Agree with the } \\
\text { system }\end{array}$ & $6(42.86)$ & $7(50.00)$ & I (7.|4) & 4.36 & 0.63 & high \\
\hline
\end{tabular}

Citation: Tangsawad S, Taneepanichskul S. Increasing smear positive-pulmonary tuberculosis cases by strengthening district TB coordinating team in low casedetection provinces, Thailand. J Lung Pulm Respir Res. 2018;5(6):202-210. DOI: 10.15406/jlprr.2018.05.00192 
"The training schedule should be set up regularly for health personnel who practice in the field of TB service and control program, this training program is very useful for health service and practice". (Respondent from hospital)

"For improve training program in the future, the training course should have more time for learning about data analysis" (respondent from hospital)

"The training time is relatively short compared to the training content. Training time should be increased and training materials for participants to study and transfer to relevant personnel to know." (Respondent from hospital)

\section{Opinion about system development and strengthening of district tuberculosis coordinating System}

All of participants agreed with the system strengthening of district TB coordinating system. For the issue of referral concluded that the system was beneficial to TB control program in district level.

"In the past, the referral system for suspected tuberculosis from health center to the hospital was not continuously processed. If the set up referral system work continuously, the TB control in district level will be effective" (respondent from hospital)

"The strengthening system help to increase case finding and referral system" (respondent from hospital and district health official)

"The tracing system for suspected cases for follow up and complete the microscopic and chest radiography were the way for detect more case finding" (respondent from hospital)

"For the reporting system, the referral form should be adapted for health worker and practitioners to practical use" (respondent from hospital)

For the issue of the role of tuberculosis coordinator in hospital (Hospital TB coordinator), all participants agreed with this issue.

"District TB coordinator from hospital and district health office have the important role in coordination and tracing system suspected $T B$ cases to complete the diagnosis and investigation, this help to improve existing TB health service in our district." (respondent from hospital and district health office)

For the role of each organization in TB control, the stakeholder including 1) Hospital setting, the hospital should have hospital TB coordinator to coordinate with other department in the hospital in TB investigation and registration and also coordinate with district health office in tracing for suspected TB cases in the community. 2) District health office setting, should have TB coordinator to coordinate with hospital TB coordinator and monitoring the health center for TB tracing mechanism to complete the investigation and treatment.

\section{Opinion about monitoring and evaluation of the system}

Most of the participants agreed with the mechanism of monitoring and evaluation process for problem solving together.

"The timing of monitoring \& evaluation process and problem solving together should be monthly, this process is the strengthening the system to go on and regularly work". (respondent from hospital)

\section{Suggestion for improve the TB coordinating system in the future}

For improving the TB coordinating system for coordinate and increase the suspected TB cases to more accessible to the health service, the participants suggested in the integration into routine work.

"The system should be integrate to the routine work in TB program for sustainable process in the future". (respondent from hospital)

"The project or in the part of strengthening system should have the regular training program for each responsible personnel to update $T B$ knowledge and ". (respondent from health center)

According to the issue of need in regular training, this reflected the high turnover rate in TB health personnel in district level.

\section{Recommendations for strengthening system for tuberculosis results from focus group}

i. The district TB coordinating team set up for TB strengthening system in district level defined the role of each participants from different organization to coordinate in TB program. If the system is mixed with the routine work, the outcome will result in a stronger coordination system for tuberculosis control program in district level among hospital, district health office and health center.

ii. The system should be continued and practice including regular improve knowledge for health personnel and should be distributed or expanded to other district to increase the detection for TB.

iii. The monitoring and evaluation process should be regular and improve the system together. The project should be monitored every 2 months or every 3 months to stimulate the work better.

\section{Discussion}

The mixed method Quasi-Experimental study with two-group control and intervention pre-post analysis. The experimental group was strengthened and set up the system for TB coordinating system. The control group worked as routine for TB services. The focus group study in the participants with system implementation. The intervention was conducted in the 9 months period the objective of the study was to increase more TB case notification in low prevalence province by set up the strengthening system for TB control. The district TB co-ordinating team had the role especially in term of increasing case notification. The team including the health personnel involve in TB control program in the district. For the overall satisfaction level of participants for strengthening system set up is in high level. The highest score is in the item of having district TB coordinator in both hospital and district level. The district TB coordinator responsible for many activities that allow health facilities to do their work such as the performance for TB health services. District $\mathrm{TB}$ coordinator also involves in many activities such as planning, organizing, implementing and evaluating for TB control program in the district. ${ }^{7}$ The district hospitals in Thailand mostly diagnose tuberculosis by microscopy and chest radiography, suspected TB cases have to processed to complete three microscopy examinations and receive follow up scheduled exams for complete investigation. The coordination between related organizations in district level support the process for complete suspected TB cases in order to complete investigation. Starting with suspected cases in communities 
and method used depends on TB symptoms and screening practice at health facilities and turnaround time for delivery on results. ${ }^{8}$ In this study, we found that a district TB co-ordinating team plays a role in improving the health service performance of TB for increasing the rate of investigation and confirmed cases in the intervention hospital. For the relative risk of TB notification cases in control hospital $(\mathrm{RR}=0.74$, 95\% CI 0.54-1.03, p-value 0.07) and intervention hospital ( $\mathrm{RR}=1.61$, $95 \%$ CI 1.04-2.51, p-value 0.03). For qualitative study, focus group analysis and recommendation on the role of each participants from different organization to coordinate in TB program, expected to be the result in a stronger coordination system for tuberculosis control program in district level. The qualitative study to explore health care providers' perception of existing barriers to access to TB services in Russia, in health care system, found that suboptimal collaboration with general health services and social services limits opportunities for care and social support to patients. ${ }^{9}$ This context alike the outcome of the situation in this research. Actually, we have to coordinate and collaborate among health services as hospital, district health office, health centers and other community worker. For the issue of continuing system and practice including regularly improve knowledge for health personnel, in this study, all of participants in district TB coordinating team need further training and also material. The qualitative study by interview and discussion in South Africa in 14 community care workers involvement in the routine care of TB patients found that they lacked understanding of how to deal with certain issues. The knowledge and training to additional access to the information about TB, particularly MDR-TB, XDR-TB, is important for them to reinforce both their own knowledge and to educate patients. ${ }^{10}$ From focus group analysis conclude that system strengthening by set up the district TB coordinating team is benefit for TB control program in district level. The coordinating process and solving the problem together helping in term of increasing the suspected cases to get investigation and diagnosis. The hospital and district TB coordinator work together to coordinate in referral and tracing of suspected cases between hospital and health center. The TB program in district level should have the TB coordinator for coordinate the network in hospital and health center.

\section{Limitation}

The study collected the secondary data from hospital so some variables might be not completed in some detail and might have some bias in the defining TB suspected group came to the hospital by themselves. The study not include children because of the diagnosis of smear positive TB in children is often missed due to non-specific symptoms and difficulties in diagnosis.

\section{Recommendations}

I. District TB coordinating team including the stuffs from hospital, district health office, health center have the important role in collaboration for TB control in district level. Having TB coordinator in hospital and district health office is the one mechanism to improve the coverage of completed investigation in suspected TB cases and leading to increase TB case notification which preceding to further TB control program implementation in community.

II. The training program for TB health personnel should be yearly set up regularly and training course should be included the guidelines for health workers at different levels of health service.

\section{Acknowledgments}

My sincere appreciation and gratitude go to Professor Surasak Taneepanichskul, M.D., Dr. Robert sedwick Chapman, for his invaluable advices and considerable contribution to this research and all participants from Banpai and Selapoom hospitals for their well cooperation and support throughout the study.

\section{Conflicts of interest}

Authors declare that there is no conflicts of interest in publishing this article.

\section{References}

1. WHO. Global tuberculosis report 2013.

2. WHO. Global tuberculosis report 2014.

3. The $4^{\text {th }}$ Surveillance of Drug resistance in Tuberculosis. Bereau of Tuberculosis Control.Department of Disease Control, Thailand; 2012.

4. Ministry of Publuc Health. National strategic plan for tuberculosis prevention, treatment and care 2016-2020, Nonthaburi, Ministry, Thailand; 2016.

5. Rieder HL. Treatment of tuberculosis: guidelines. 4th ed. Interternational Union Against Tuberculosis and Lung Disease.WHO/HTM/TB/2009.420; 2002.

6. National Tuberculosis Control Programme Guidelines. Thailand; 2013.

7. WHO. Management of tuberculosis training for district TB coordinators. 2018.

8. Musoke J, Michel LA. Characteristics of tuberculosis patients and the evaluation of compliance to the national TB management guidelines at clinics in a rural community from Mpumalunga province, South Africa. $S$ Afr J of Infect Dis. 2016;31(4):135-137.

9. Dimitrova B, Balabanova D, Atun R, et al. Health service providers perception of barriers to tuberculosis care in Russia. Health Policy and Planning. 2006;21(4):265-274.

10. Okeyo I, Dowse R. Community care worker perceptions of their roles in tuberculosis care and their information needs. Health SA Gesondheid. 2016;21:245-252. 